\title{
Retraction Note: Rainfall-type landslide warning and sports public service performance evaluation based on data anomaly detection
}

\author{
Ni Dai ${ }^{1} \cdot$ Yi Zhang $^{1}$
}

Published online: 18 November 2021

(c) Saudi Society for Geosciences 2021

Retraction Note: Arabian Journal of Geosciences (2021) 14: 1747

https://doi.org/10.1007/s12517-021-08035-w

The Editor-in-Chief and the Publisher have retracted this article because the content of this article is nonsensical. The peer review process was not carried out in accordance with the Publisher's peer review policy. Author Yi Zhang has not responded to correspondence regarding this retraction. The Publisher has not been able to obtain a current email address for author Ni Dai.

The original article can be found online at https://doi.org/10.1007/ s12517-021-08035-w

Yi Zhang

daini163163@163.com

1 Physical Education College of Jilin University, Changchun, Jilin 130021, China 